\title{
A Twist in the Tale: TWIST1-SOX2 Axis Governs ABCG2-Mediated Paclitaxel Resistance of Breast Cancer Stem Cells
}

\author{
Pritha Mukherjee and Urmi Chatterji* \\ Department of Zoology, University of Calcutta, India \\ *Corresponding author: UrmiChatterji, Cancer Research Laboratory, Department of ZoologyUniversity of Calcutta, 35 Ballygunge Circular Road, \\ Kolkata-700 019, India
}

Submission: November 11, 2017; Published: July 18, 2018

\begin{abstract}
Epithelial-mesenchymal transition (EMT) is an important process during development by which epithelial cellsb acquire mesenchymal, fibroblastlike properties and show reduced intercellular adhesion and increased motility.The identification of epithelial-mesenchymal plasticity of breast cancer stem cells provided another level of complexity regarding development of strategies to eliminate these lethal seeds of breast cancer. In determining the association between Sox2, cell migration and expression of EMT markers, we found a persistently high expression of Twist1 and its apparent lack of EMT-like properties during migratory arrest of MDA-MB-231 cells, even after paclitaxel treatment of Sox2-silenced cells. The role of Sox2-dependent Twist1 in maintaining stemness was more prominent when Sox2 expression was high in brCSCs. It can be presumed now that Twist1 expression in presence or absence of Sox2 defines the precise mechanism underlying the possible role of Twist1 in crossroads of pluripotency and EMT of breast cancer stem cells.
\end{abstract}

Keywords: Breast cancer; Breast cancer stem cells; Pluripotency;Epithelial-to-mesenchymal transition;Chemoresistance; SOX2; Chemotherapy; TWIST1; ABCG2;Gene silencing

\section{Introduction}

The major caveat in treatment of breast cancer patients is the possibility of recurrence, even afterimplementation of successful therapeutic strategies. Asmall population of relatively quiescent chemo-resistant cancer stem cells(CSCs) have been implicated for disease relapse. CSCs can escape the deleterious effects of chemotherapy through a variety of mechanisms and thus mediate chemoresistance. Therefore, targeting CSCs may prove to be a useful approach for exploiting key mechanisms that sustain overall tumor survival and overcoming drug treatment failures that ultimately lead to recurrence and death [1]. Different factors mediate chemoresistance in CSCs, like ATP-binding cassette (ABC) transporters [2,3]. Aldehyde dehydrogenase (ALDH1) activity [4,5]. Bcl-2 protein family members [6-8]. Altered DNA damage responses [9-11] and CSC-related signaling components [12-15].

Epithelial-Mesenchymal Traits and Survival of Cancer Stem Cells

Advances in cancer research have focused on the role of epithelial-to-mesenchymal transition (EMT) and CSCs in tumor progression, metastasis and treatment resistance $[16,17]$. Epithelial-to-mesenchymal transitioned tumor cells have been reported to possess increased motility and invasiveness, tumorpropagating potential, and resistance to apoptosis and anti-tumor drugs $[18,19]$. EMT is triggered by a number of distinct molecular processes including the expression of specific cell-surface proteins and the activation of transcription factors (TFs). EMT-TFs belong to different families, including SNAI1 (or Snail) and SNAI2 (or Slug), two ZEB factors, ZEB1 and ZEB2, and Twist [20,21]. The biological link between EMT phenotypes and CSCs has recently been studied in many types of cancer including prostrate, pancreatic, ovarian and breast [22-24]. In breast cancer, it has been reported that the overexpression of Twist, Snail or FOXC2 not only rendered the breast cancer cells with more mesenchymal properties, but also an increased expression of $\mathrm{CD} 44^{+} / \mathrm{CD} 24^{-/ / \text {low }}$ breast CSC markers and an increased mammosphere forming efficiency $[16,25]$. Prostate cancer cells with an EMT phenotype showed increased expressions of Sox2, Nanog, Pou5F1, lin28B and Notch1, concomitant with an enhanced sphere-forming ability [26]. In pancreatic cancer, hypoxia induced upregulation of FOXA2, accompanied by EMT, down-regulation of E-cadherin and upregulation of mesenchymal markers, viz., Vimentin, Slug, Snail and Twist [27].

\section{The Dual Role of Twist in Cancer Stem Cells}

The role of EMT during early development and differentiation is critical to the survival of the embryo, as it is for survival of tumors. However, the main difference between normal development and pathological processes is that cellular and molecular events follow highly regulated spatial and temporal plans during development, whereas during transformation the order of events may be stochastic or bypassed. During tumorigenesis, EMT increases 
the motility and invasiveness of cancer cells, and malignant transformation is oftentriggered by specific signaling pathways which promote EMT [28]. Oncogenic factors such as Notch, Wnt, Hh, TGF- $\beta$, peptide growth factors, Src, Ras, Ets, and integrin act as EMT-initiating signaling components inducing well-differentiated epithelial cells to convert into motile mesenchymal cells via the activation of multiple transcription factors, including Twist, Snail, Slug and ZEB [29].Interestingly, these factors have also been shown to regulate both self-renewal and oncogenesis of cancer stem cells from different tumor sites [30-33]. A strong relationship thus exists between stemness and EMT which ultimately governs the aggressive nature of cancer stem cells and their chemoresistance[16,34].

Over the past decade, the reactivation of Twist has been described as a marker of poor prognosis in an impressive array of human cancers [35]. Growing evidencesubstantiates that these cancers modulate the embryonic functions of Twist, and grant them oncogenic and metastatic properties. Twist up-regulation is observed in many cancers such as melanoma, T-cell lymphoma, prostate cancer, gastric carcinomas, rhabdomyosarcomas, and breast cancer [36-41]. Mechanistically, overexpression of Twist has been shown to inhibit apoptosis and interfere with p53 tumor suppressor functions [42].

Although Twistplays a major role duringEMT [43,44], the emerging role which Twistplays at the crossroads of EMT and maintenance of CSCs is a recent breakthrough. Twist has been associated with stem cell compartments during embryogenesis [45]. Overexpression of Twist in an in vitromouse embryonic stem cell model system prevents premature muscle cell differentiation, indicating its functions within the stem cell context [46]. During development, Twist has been shown to be upregulated through the Sonic hedgehog pathway and in turn upregulates Gli-1 [47]. In pathological conditions, Twist is overexpressed in more than $60 \%$ of breast tumors and is associated with loss of E-cadherin expression and increased genetic instability [48]. Overexpressing Twist in breast cells increased invasiveness, motility, angiogenesis, and resistance to radiation [43], indicating its active and dual role in both EMT and maintenance of stem cell characteristics. Studies are presentlyfocussing onidentification and characterization of the role of Twist in generating cancer stem cells. It has been shown that overexpression of Twist in MCF7 cells could significantly increase the stem cell population, as identified by an increase in the number of $\mathrm{CD}_{4} 4^{+} \mathrm{CD} 24^{-/ \mathrm{low}}$ and $\mathrm{ALDH}^{+}$cells [49].Several evidences now support that there is a direct role of Twist1 in regulating and maintaining stemness of cancer stem cells together with some major pluripotency genes independent of its role in EMT.

\section{The Twist1-Sox2 Axis Governs Chemoresistance of Cancer Stem Cells}

CSCs have been operationally defined through their ability to generate tumors with high efficiency when injected in limiting dilutions into immune-compromised mice [50-55]. Cancer recurrence has also been attributed to thisfiend population of CSCs which are not eliminated by conventional chemotherapy, primarily because of elevated expression of drug efflux pumps $[56,57]$. In addition, the fact that chemotherapy enriches the CSC population within a tumor poses a greater threat for the patient $[57,58]$. Therefore, modulation of factors responsible for elevating expression of drug transporters points toward a more effective and complete cure for cancer patients.

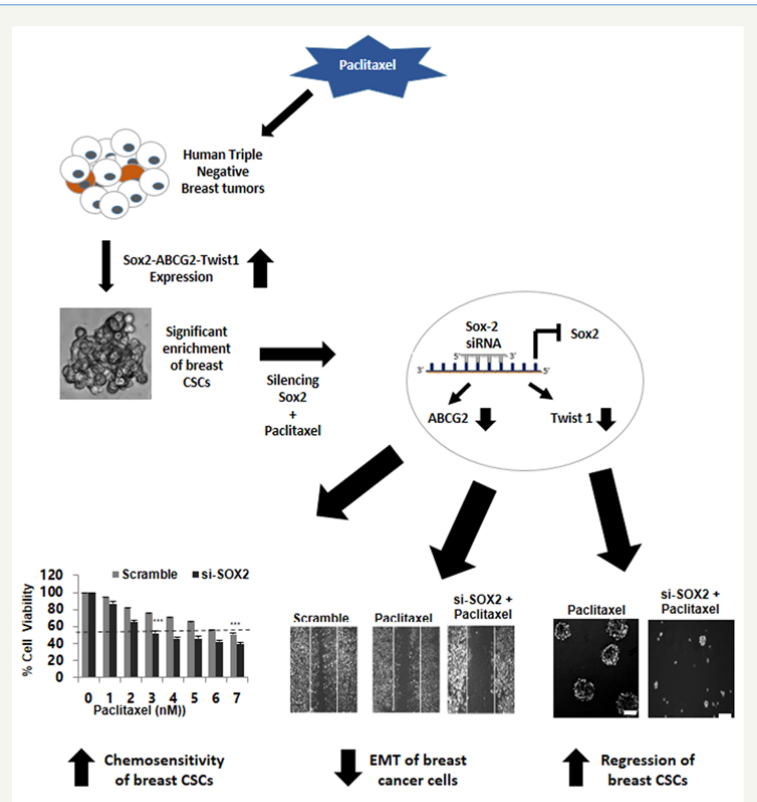

Figure 1: Paclitaxel treatment of human triple negative breast tumors targeted the bulk epithelial cancer cells (shown in white) leaving behind the cancer stem cells (CSCs; shown in orange) that are drug resistant. Chemo-treatment alters the gene expression profile of cancer stem cells in comparison to their normal counterpart, such as SOX2, TWIST1 and ABCG2, which are significantly upregulated in paclitaxel-treated triple negative breast tumors. This cascade contributes topluripotency and stemness properties of breast CSCs, with enhanced mammosphere formation and migratory propensity. Silencing SOX2 with siRNA leads to the down regulation of ABCG2 and TWIST1, confirming that SOX2 governs the expression of these two major CSC markers. Further, paclitaxel treatment in conjunction to si-SOX2, led to i) increased chemosensitivity of breast CSCs to the drug, ii) regulates epithelial-to-mesenchymal transition (EMT) and induces migratory arrest that sustains even after drug removal, simulating a post-chemo treatment condition in patients, and iii) reduces the sphere forming efficiency of CSCs, thus rendering them more susceptible to the anti-cancer effects of paclitaxel. 
Among the several genes that belong to the survival and maintenance family of CSCs, Sox2 stands out to be a major contributor for tumor initiation and cancer stem cell functions. This transcription factor plays an essential role in cell fate determination, thereby regulating developmental processes [59]. Aberrant expression of Sox2 has been reported in many types of cancers and is correlated with the persistent presence of CSCs[60,61]. Sox2 has also been linked to drug resistance in several studies.In a recent studyon breast cancer, we have demonstrated that paclitaxel treatment confers aTwist1-independent reduction of invasiveness in triple negative breast cancer cells. Reduction in invasiveness was more prominent when Sox2-silenced cells were treated with paclitaxel which continued to remain retarded even after drug removal[58]. Expression of Twist1 however remained significantly high in the Sox2-silenced MDA-MB-231 cells, both during and post paclitaxel treatment. There was an apparent lack of Twist1 involvement in migrationof both paclitaxel-treated MDAMB-231 cells and Sox2-silenced MDA-MB-231 cells. Subsequently, clarification of its role in mammosphereswas necessary. Therein we found that paclitaxel-treated mammospheres re-grown as secondary spheres retained a high expression of Twist1 suggesting its major contribution in maintaining stem-like nature and chemoresistance of mammospheres rather than being a controller of EMT in cancer stem cells[58]. However, silencing Sox2 inmammospheres not only reduced their capacity to form secondary spheresbut enhanced chemosensitivity to paclitaxel (Figure 1). This was accompanied bydown regulation of Twist1 expression in both secondary spheres and cells cultured under adherent conditions, and was sustained even after drug removal, corroborating a post-chemotherapy condition. Previous literature and current data suggest that Sox 2 and Twist 1 are major regulators of CSC features in cancers. Specifically, based on Sox2-silencing experiments and chemosensitivity assays, it may be concluded that the Sox2-ABCG2-Twist1 axis plays a key role in regulating chemoresistance and tumorigenicity in triple negative brCSCs. Therefore, obliterating Sox2-Twist1 expression specifically in brCSCs before or during chemotherapy is a possible approach to eliminate the brCSC population within a tumor, with a promise to prevent post-chemotherapy recurrences in future.

\section{References}

1. Abdullah LN, Chow EK (2013) Mechanisms of chemoresistance in cancer stem cells. Clin Transl Med 2(1): 3 .

2. Scharenberg CW, Harkey MA, Torok SB (2002) The ABCG2 transporter is an efficient Hoechst 33342 efflux pump and is preferentially expressed by immature human hematopoietic progenitors. Blood 99(2): 507-512.

3. Jonker JW, Merino G, Musters S, van Herwaarden AE, Bolscher E, et al (2005) The breast cancer resistance protein BCRP (ABCG2) concentrates drugs and carcinogenic xenotoxins into milk. Nat Med 11(2): 127-129.

4. Ginestier C, Hur MH, Charafe JE, Monville F, Dutcher J, et al (2007) ALDH1 is a marker of normal and malignant human mammary stem cells and a predictor of poor clinical outcome. Cell Stem Cell 1(5): 555-567.

5. Dylla SJ, Beviglia L, Park IK, Chartier C, Raval J, et al. (2008) Colorectal cancer stem cells are enriched in xenogeneic tumors following chemotherapy. PLoS One 3(6): e2428.
6. Konopleva M, Zhao S, Hu W, Jiang S, Snell V, et al. (2002) The antiapoptotic genes $\mathrm{Bcl}-\mathrm{X}(\mathrm{L})$ and $\mathrm{Bcl}-2$ are over-expressed and contribute to chemoresistance of non-proliferating leukaemic $\mathrm{CD} 34^{+}$cells. $\mathrm{Br} \mathrm{J}$ Haematol 118(2): 521-534.

7. Madjd Z, Mehrjerdi AZ, Sharifi AM, Molanaei S, Shahzadi SZ, et al. (2009) $\mathrm{CD}_{4} 4^{+}$cancer cells express higher levels of the anti-apoptotic protein Bcl-2 in breast tumours. Cancer Immun 9: 4.

8. Todaro M, Alea MP, Di Stefano AB, Cammareri P, Vermeulen L, et al. (2007) Colon cancer stem cells dictate tumor growth and resist cell death by production of interleukin-4. Cell Stem Cell 1(4): 389-402.

9. Bao S, Wu Q McLendon RE, Hao Y, Shi Q et al. (2006) Glioma stem cells promote radioresistance by preferential activation of the DNA damage response. Nature 444(7120):756-760.

10. Gallmeier E, Hermann PC, Mueller MT, Machado JG, Ziesch A, et al. (2011) Inhibition of ataxia telangiectasia- and Rad3-related function abrogates the in vitro and in vivo tumorigenicity of human colon cancer cells through depletion of the CD133(+) tumor-initiating cell fraction. Stem Cells 29(3): 418-429.

11. Venkatesha VA, Parsels LA, Parsels JD, Zhao L, Zabludoff SD, et al. (2012) Sensitization of pancreatic cancer stem cells to gemcitabine by Chk1 inhibition. Neoplasia 6: 519-525.

12. Zhao C, Blum J, Chen A, Kwon HY, Jung SH, et al. (2007) Loss of betacatenin impairs the renewal of normal and CML stem cells in vivo. Cancer Cell 12(6): 528-541.

13. Mc Auliffe SM, Morgan SL, Wyant GA, Tran LT, Muto KW, et al. (2012) Targeting Notch, a key pathway for ovarian cancer stem cells, sensitizes tumors to platinum therapy. Proc Natl Acad Sci USA 109(43): E2939-E2948.

14. Song Z, Yue W, Wei B, Wang N, Li T, et al. (2011) Sonic hedgehog pathway is essential for maintenance of cancer stem-like cells in human gastric cancer. PLoS One 6(3): e17687.

15. Yip NC, Fombon IS, Liu P, Brown S, Kannappan V, et al. (2011) Disulfiram modulated ROS-MAPK and NFкB pathways and targeted breast cancer cells with cancer stem cell-like properties. Br J Cancer 104(10): 15641574

16. Mani SA, Guo W, Liao MJ, Eaton EN, Ayyanan A, et al. (2008) The epithelial-mesenchymal transition generates cells with properties of stem cells. Cell 133(4): 704-715.

17. Morel AP, Lièvre $M$, Thomas C, Hinkal G, Ansieau S, et al. (2008) Generation of breast cancer stem cells through epithelial-mesenchymal transition. PLoS One 3(8): e2888.

18. Polyak K, Weinberg RA (2009) Transitions between epithelial and mesenchymal states: acquisition of malignant and stem cell traits. Nat Rev Cancer 9(4): 265-273.

19. Singh A, Settleman J (2010) EMT, cancer stem cells and drug resistance: an emerging axis of evil in the war on cancer. Oncogene 29(34): 47414751.

20. Nieto MA, Cano A (2012) The epithelial-mesenchymal transition under control: global programs to regulate epithelial plasticity. Semin Cancer Biol 22(5-6): 361-368.

21. Guo W, Keckesova Z, Donaher JL, Shibue T, Tischler V, et al. (2012) Slug and Sox9 cooperatively determine the mammary stem cell state. Cell 148(5): 1015-1028.

22. Zhou P, Li B, Liu F, Zhang M, Wang Q, et al. (2017) The epithelial to mesenchymal transition (EMT) and cancer stem cells: Implication for treatment resistance in pancreatic cancer. Mol Cancer 16(1): 52.

23. Dong C, Wu Y, Yao J, Wang Y, Yu Y, et al. (2012) G9a interacts with Snail and is critical for Snail-mediated E-cadherin repression in human breast cancer. J Clin Invest 122(4): 1469-1486. 
24. Zhou W, Lv R, Qi W, Wu D, Xu Y, et al. (2014) Snail contributes to the maintenance of stem cell-like phenotype cells in human pancreatic cancer. PLoS One 9(1): e 87409.

25. Hollier BG, Tinnirello AA, Werden SJ, Evans KW, Taube JH, et al. (2013) FOXC2 expression links epithelial-mesenchymal transition and stem cell properties in breast cancer. Cancer Res 73(6): 1981-1992.

26. Dembinski JL, Krauss S (2009) Characterization and functional analysis of a slow cycling stem cell-like subpopulation in pancreas adenocarcinoma. Clin Exp Metastasis 26(7): 611-623.

27. Liu L, Salnikov AV, Bauer N, Aleksandrowicz E, Labsch S, et al. (2014) Triptolide reverses hypoxia-induced epithelial-mesenchymal transition and stem-like features in pancreatic cancer by NFkappaBdownregulation. Int J Cancer 134(10): 2489-2503

28. Boyer B, Vallés AM, Edme N (2000) Induction and regulation of epithelialmesenchymal transitions. Biochem Pharmacol 60(8): 1091-1099.

29. Puisieux A, Brabletz T, Caramel J (2014) Oncogenic roles of EMT-inducing transcription factors. Nat Cell Biol 16(6): 488-494.

30. Taipale J, Beachy PA (2001) The Hedgehog and wnt signaling pathways in cancer. Nature 411(6835): 349-354

31. Varnum FB, Xu L, Brashem SC, Nourigat C, Flowers D, et al. (2000) Pluripotent, cytokine-dependent, hematopoietic stem cells are immortalized by constitutive Notch1 signaling. Nature Med 6(11): 12781281.

32. Bhardwaj G, Murdoch B, Wu D, Baker DP, Williams KP, et al. (2001) Sonic hedgehog induces the proliferation of primitive human hematopoietic cells via BMP regulation. Nature Immunol 2(2): 172-180.

33. Chan EF, Gat U, McNiff JM, Fuchs E (1999) A common human skin tumour is caused by activating mutations in beta-catenin. Nat Genet 21(4): 410413.

34. Fabregat I, Malfettone A, Soukupova J (2016) New insights into the crossroads between EMT and stemness in the context of cancer. J Clin Med 5(3): pii. E37.

35. Jing Y, Sendurai AM, Robert AW (2006) Exploring a new twist on tumor metastasis. Cancer Res 66(9): 4549-4552.

36. Hoek K, Rimm DL, Williams KR, Zhao H, Ariyan S, et al. (2004) Expression profiling reveals novel pathways in the transformation of melanocytes to melanomas. Cancer Res 64(15): 5270-5282.

37. Doorn R, Dijkman R, Vermeer MH, Out-Luiting JJ, Helmer REM, et al.(2004) Aberrant expression of the tyrosine kinase receptor EphA4 and the transcription factor twist in Sézary syndrome identified by gene expression analysis. Cancer Res 64(16): 5578-5586.

38. Kwok WK, Ling MT, Lee TW, Lau TC, Zhou C, et al. (2005) Up-regulation of TWIST in prostate cancer and its implication as a therapeutic target. Cancer Res 65(12): 5153-5162.

39. Rosivatz E, Becker I, Specht K, Fricke E, Luber B, et al. (2002) Differential expression of the epithelial-mesenchymal transition regulators snail, SIP1, and twist in gastric cancer. Am J Pathol 161(5): 1881-1891.

40. Maestro R, Dei Tos AP, Hamamori Y, Krasnokutsky S, Sartorelli V, et al. (1999) Twist is a potential oncogene that inhibits apoptosis. Genes Dev 13(17): 2207-2217.

41. Mironchik Y, Winnard PT, Vesuna F, Kato Y, Wildes F, et al. (2005) Twist overexpression induces in vivo angiogenesis and correlates with chromosomal instability in breast cancer. Cancer Res 65(23): 1080110809.

42. Stasinopoulos IA, Mironchik Y, Raman A, Wildes F, Winnard P, et al. (2005) HOXA5-twist interaction alters p53 homeostasis in breast cancer cells. J Biol Chem 280(3): 2294-2299.
43. Yang J, Mani SA, Donaher JL, Ramaswamy S, Itzykson RA, et al. (2004) Twist, a master regulator of morphogenesis, plays an essential role in tumor metastasis. Cell 117(7): 927-939.

44. Je EC, Lca BS, Ga GA (2013) The role of transcription factor TWIST in cancer cells. J Genet Syndr Gene Ther S2:002

45. Gerecht-Nir S, Dazard JE, Mashiach GM, Osenberg S, Botvinnik A, et al. (2005) Vascular gene expression and phenotypic correlation during differentiation of human embryonic stem cells. Dev Dyn 232(2): 487 497.

46. Rohwedel J, Horak V, Hebrok M, Fuchtbauer EM, Wobus AM (1995) M-twist expression inhibits mouse embryonic stem cell-derived myogenic differentiation in vitro. Exp Cell Res 220(1): 92-100.

47. Villavicencio EH, Walterhouse DO, Iannaccone PM (2000) The sonic hedgehog-patched-gli pathway in human development and disease. Am J Hum Genet 67(5): 1047-1054.

48. Vesuna F, van Diest P, Chen JH, and Raman V (2008). Twist is a transcriptional repressor of E-cadherin gene expression in breast cancer. BiochemBiophys Res Commun 367(2): 235-241.

49. Vesuna F, Lisok A, Kimble B, Raman V (2009) Twist modulates breast cancer stem cells by transcriptional regulation of CD24 expression. Neoplasia 11(12): 1318-1328.

50. Alison MR, Lim SM, Nicholson LJ (2011) Cancer stem cells: problems for therapy? J Pathol 223(2): 147-161

51. Lapidot T, Sirard C, Vormoor J, Murdoch B, Hoang T, et al. (1994) A cell initiating human acute myeloid leukaemia after transplantation into SCID mice. Nature 367(6464): 645-648.

52. Muhammad AH, Max SW, Adalberto BH, Sean JM, Michael FC (2003) Prospective identification of tumorigenic breast cancer cells. Proc Natl Acad Sci USA 100(7): 3983-3988

53. Singh SK, Hawkins C, Clarke ID, Squire JA, Bayani J, et al. (2004) Identification of human brain tumour initiating cells. Nature 432(7015): 396-401.

54. O'Brien CA, Pollett A, Gallinger S, Dick JE (2007) A human colon cancer cell capable of initiating tumour growth in immunodeficient mice. Nature 445(7123): 106-110.

55. Hermann PC, Huber SL, Herrler T, Aicher A, Ellwart JW, et al. (2007) Distinct populations of cancer stem cells determine tumor growth and metastatic activity in human pancreatic cancer. Cell Stem Cell 1(3): 313323.

56. Dean M (2009) ABC transporters, drug resistance, and cancer stem cells. J Mammary Gland Biol Neoplasia 14(1): 3-9.

57. Achuthan S, Santhoshkumar TR, Prabhakar J, Nair SA, Pillai MR (2011) Drug-induced senescence generates chemoresistantstemlike cells with low reactive oxygen species. J Biol Chem 286(43): 37813-37829.

58. Mukherjee P, Gupta A, Chattopadhyay D, Chatterji U (2017) Modulation of SOX2 expression delineates an end-point for paclitaxel-effectiveness in breast cancer stem cells. Sci Rep 7(1): 9170.

59. Sarkar A, Hochedlinger K (2013) Thesox family of transcription factors: versatile regulators of stem and progenitor cell fate. Cell Stem Cell 12(1): 15-30.

60. Leis O, Eguiara A, Lopez AE, Alberdi MJ, Hernandez GS, et al. (2012) Sox2 expression in breast tumours and activation in breast cancer stem cells. Oncogene 31(11): 1354-1365.

61. Lundberg IV, Edin S, Eklöf V, Öberg Å, Palmqvist R, et al. (2016) SOX2 expression is associated with a cancer stem cell state and downregulation of CDX2 in colorectal cancer. BMC Cancer 16: 471. 
(c) (i) Creative Commons Attribution 4.0 International License

For possible submissions Click Here

Submit Article
SBB of bocononest

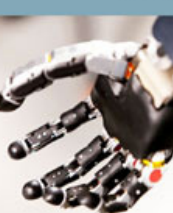

\section{Significances of Bioengineering \& Biosciences}

\section{Benefits of Publishing with us}

- High-level peer review and editorial services

- Freely accessible online immediately upon publication

- Authors retain the copyright to their work

- Licensing it under a Creative Commons license

- Visibility through different online platforms 